\title{
Combining behavioral economics and field experiments to reimagine early childhood education
}

\author{
JOHN A. LIST \\ The University of Chicago, IL, USA and National Bureau of Economic Research, MA, USA \\ ANYA SAMEK \\ University of Southern California, CA, USA \\ DANA L. SUSKIND * \\ The University of Chicago, IL, USA
}

\begin{abstract}
Behavioral economics and field experiments within the social sciences have advanced well beyond academic curiosum. Governments around the globe as well as the most powerful firms in modern economies employ staffs of behavioralists and experimentalists to advance and test best practices. In this study, we combine behavioral economics with field experiments to reimagine a new model of early childhood education. Our approach has three distinct features. First, by focusing public policy dollars on prevention rather than remediation, we call for much earlier educational programs than currently conceived. Second, our approach has parents at the center of the education production function rather than at its periphery. Third, we advocate attacking the macro education problem using a public health methodology, rather than focusing on piecemeal advances.
\end{abstract}

Submitted 18 January 2017; accepted 9 February 2017

\section{Introduction}

Educational disparities are one of the most significant public policy issues of our time, particularly in the United States. The question as to why the substantial resources that have been committed to public education over the past half century have had seemingly little effect on closing the achievement gap remains unresolved. One key feature of the educational expenditure pattern, however, is that it has focused on remediation rather than prevention, with the majority

\footnotetext{
* Correspondence to: Department of Surgery, Division of Otolaryngology, University of Chicago Medicine, 5841 South Maryland Avenue, MC 1035, Chicago, IL 60637, USA. Email: dsuskind@ surgery.bsd.uchicago.edu
} 
of dollars supporting our formal education system - preschool through to the 12th grade. Such expenditure patterns represent a developmental sciencepolicy disconnect.

Early childhood education, which traditionally focuses on preschool, is no longer aligned with the growing body of science, which shows that cognitive gaps emerge well before the first day of preschool and that disparities in parental investment as they relate to children's foundational brain development are among the root causes of the achievement gap. Recent research in the areas of early childhood development, neuroscience, psychology, and economics reveals that preschool interventions come too late in human capital development and important 'dynamic complementarities' may exist in educational investment - early returns to education, particularly parent investment, begets future educational investment and even higher subsequent returns. Placed within a population context, the science compels us to redefine early childhood as a public health issue - one that merits a robust population health response targeting parental investment in child development, beginning at birth.

At the center of this new policy approach is the use of behavioral economics and field experiments to systematically engage and catalyze parental/caregiver investment and bring it to scale as a key driver for educational equity, ultimately closing the science-policy disconnect. Recent years have seen the emergence of using insights from behavioral economics in domains of education and health. One such example is the role of incentives, which can encourage parents to attend parenting sessions and lower the 'cost' of investing in their children. In a recent study, Fryer and colleagues investigated the impact of a parenting intervention with incentives on preschool children's cognitive and non-cognitive achievement (Fryer et al., 2015). The incentives provided through this program both encouraged parents to attend the classes and increased the time parents spent with their children. The study found a strong impact of the parenting intervention on non-cognitive skills (Fryer et al., 2015). Moreover, parenting interventions show longer-lasting effects, as parents can continue to support and invest in their children as they grow older. While behavioral economics has made inroads in a number of areas, including improvements in school settings (Fryer, 2011; Fryer et al., 2012; List \& Samek, 2015; Levitt et al., 2016), comparatively less attention has been paid to parents.

In what follows, the 'Introducing the education production' section describes how investing in schools, parents, or children affects both inputs and outputs. This section also provides insights into the kinds of questions that remain open in our understanding of the education production function. 
The next section, entitled 'The importance of the early years: implications for policy', provides a summary of the science - from foundational brain development (ages $0-3$ ) through to the early childhood years (through to age 5 ). This section leverages recent research in the areas of early childhood development, neuroscience, psychology, and economics. The 'Inserting behavioral economics into early childhood education (ages $0-5$ )' section highlights a few examples of how behavioral economics can be inserted into early education programs. These examples are based on research conducted in the United States; however, studying their applications in other countries is also of clear interest for future work. The 'Reimagining early childhood (ages $0-5$ ): a public health approach' section proposes a new approach to early childhood education, focusing on a public health approach. The 'Epilogue' section concludes and describes our views on a path forward.

\section{Introducing the education production function}

A simple framework that economists have used to help understand the relationship between how educational inputs, such as parent effort and teacher effort, map onto outputs like lifetime earnings is the education production function. The basic thought experiment behind the education production function is similar to the process the typical Economics 101 firm uses to convert inputs like labor and capital into a physical output. However, the dynamics of producing education requires adding a bit more complexity to the production functions students learn about in their first year of undergraduate study. In this section, we briefly sketch out these additional dynamics and relate them to research on the policy question of increasing educational achievement in the United States.

A representative mathematical formulation of the education production function for a child of age $t$ can be posed as follows:

$$
a_{t}=f\left(p_{t}, s_{t}, c_{t}, a_{t-1}\right),
$$

where $p_{t}$ is parental investments at age $t, s_{t}$ is the school investments by teachers or peers at age $t$, and $c_{t}$ is investments by the child at age $t$. Examples of these investments include parental help on homework, teacher quality or effort, and child study time. The function $f(\cdot)$ maps each combination of these inputs and produces educational achievement, $a_{t}$. Examples of $a_{t}$ include grades, test score performance, lifetime earnings, or even health and criminal activity.

Importantly, achievement at age $t$ is not only affected by investments in that time period, but also by the level of achievement and investments at earlier ages, $a_{t-1}$. Figure 1 illustrates these mechanics with the parent, school, and 


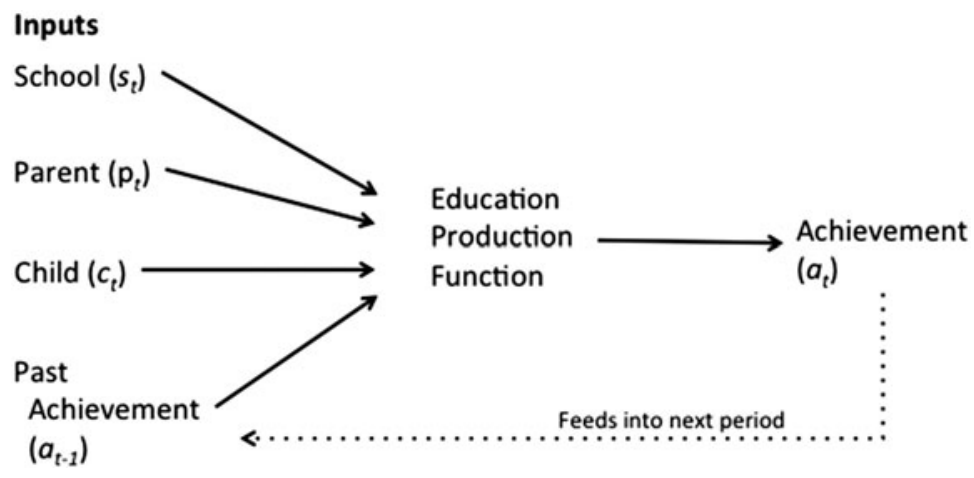

Figure 1. Flow chart denoting the relationship between inputs into the production of education and educational achievement

child investments being converted into educational achievement, which then maps back onto the investment decisions in the next time period.

The value in thinking about the education production function is that it organizes the questions researchers must answer in order to more effectively design interventions to ameliorate the educational achievement gaps in the United States (or, perhaps more appropriately, to shift the population outcome distribution rightward). One important example is related to the claim of 'skills begetting skills'. If achievement early in life leads to more productive investments later in life, then early investments will effectively compound over time.

Yet, if achievement early in life is a perfect substitute for current achievement, then investments should be focused on the specific time period when they are most productive (accounting for cost). Another important example to consider is the interaction between the different investments. To see why this is important, consider the question of a school district investing in an after-school program. If this schooling investment is complementary to child investments, then it could reap large returns in educational achievement. However, if schooling and child investments are substitutes, then children might reduce their investments one-for-one and the after-school program will lead to no change in achievement.

All told, there are three important relationships that need to be explored before one can advance meaningful public policies within education circles:

1. How introduction of incentives in time period $t$ impacts effort investment in time period $t$ and subsequent periods.

2. How changes in one effort level impact investment in other parts of the production function contemporaneously and dynamically. 
3. How effort level changes in time period $t$ impact outputs in time period $t$ and in subsequent periods.

While important research has been done on the education production function, there is much more to be done to understand these three relationships. Most research to date has focused on varying one input and measuring the eventual effect that input has on achievement. Often, this is just studied in one specific time period. However, the education production function tells us that this approach only gives a piece of the story because it ignores two key ingredients: the interaction between investments and the interactions that occur over time. Instead, a more systematic approach that focuses on measuring all inputs and subsequent achievement could lead to more effective policy interventions. Furthermore, it would generate the sort of knowledge that could accumulate across experiments.

\section{The importance of the early years: implications for policy}

Science reveals that disparities in the early learning environment of children from birth to five years of age are among the root causes of the achievement gap. By as early as nine months of age, infants born into poverty score lower in cognitive development than their more affluent peers. This disparity triples by the age of two (Halle et al., 2009). Adult-child verbal interactions are a key example of where the disparities in parental investments are most evident. In their seminal research, Hart and Risley found that children from low socioeconomic status (SES) backgrounds heard 30 million fewer words by their fourth birthday than high SES children (Hart \& Risley, 1995). This profound disparity has been argued to invoke a cascade of consequences for cognitive development, school readiness, academic achievement, and later life course outcomes (Forget-Dubois et al., 2009). Children from low SES households score lower than their peers on academic achievement tests and suffer from higher high school drop-out rates, lower entry rates to college, and lower rates of college completion, as well as fewer economic opportunities (Bailey \& Dynarski, 2011).

A robust body of research has since revealed that the quality of adult-child interactions is equally as significant as the quantity of parental language input. Children raised in poverty have been found to experience less lexical diversity, syntactic complexity, and gesturing, as well as fewer conversational turns and open-ended questions (Nelson et al., 2007; Raver et al., 2013; Brito et al., 2016). SES and maternal education are also positively associated with maternal sensitivity, positive regard, and cognitive stimulation during parent-child interactions, which in turn contribute to children's cognitive development (Lugo-Gil 
\& Tamis-LeMonda, 2008; Mistry et al., 2008). In addition, according to national time diaries, highly educated mothers (college degree or higher) spend 4.5 more hours each week interacting with their children than less educated mothers and they do so in more developmentally appropriate ways (Guryan et al., 2008). This is particularly important because parental time investment has also been shown to have causal effects on children's cognitive development (Villena-Roldán \& Ríos-Aguilar, 2012). The impact of parent-child interactions is far-reaching, particularly during the early years of a child's development.

\section{The etiology of the challenge: parental investment and foundational brain development in the earliest years (ages 0-3)}

Educational disparities appear long before preschool and indicate a need for interventions to occur before the onset of formal schooling. Their etiology can be traced back to inequities in parental investment in early learning environments, which inhibit foundational brain development for all children and disproportionately affects children living in poverty. Research reveals that $85 \%$ of physical brain development occurs in the first three years of life, with 700-1,000 new neuronal connections being made each second. This exponential brain growth is driven primarily by caregiver input. As a whole, the literature suggests that without sufficient parental investment - rich language environments, parent-child attachment, caregiver responsiveness, and adult-child exchange - the vast neuroplasticity of a child's brain remains underutilized and the rate of learning and intellectual capacity is severely curtailed (Nelson et al., 2007; Fernald et al., 2013; Raver et al., 2013). By five years of age, less than half of low SES children are ready for school compared to $75 \%$ of high SES children (Murphey et al., 2013).

A young child's social emotional development and executive function skills (considered 'soft skills' and sometimes referred to by economists as 'non-cognitive' skills) are also concomitantly adversely impacted by the lack of caregiver investment. Impulse control, focus of attention, and working memory, for example, have been found to be critical for taking advantage of learning opportunities. By the age of four (when executive function can reliably be tested), children who lived a greater number of years in poverty and were exposed to greater financial strain between 15 and 48 months of age performed significantly worse on a battery of executive functions tests (Raver et al., 2013). Taken together, cognitive development and executive function skill formation are now both understood to be significant in determining academic trajectories (Heckman, 2000; Ursache et al., 2012; Blair \& Raver, 2014). A child's foundational brain development encompasses both, making it vulnerable to both the quantity and quality of parent-child interactions. 
Complementing this line of research is a burgeoning neuroimaging literature that reveals physical correlates to these neurocognitive findings, specifically SES impacts in brain regions critical for academic trajectories (Noble et al., 2012). A recent neonatal electroencephalogram (EEG) study demonstrates no evidence of SES-related brain differences at birth, while other studies reveal subsequent evidence of SES-related EEG differences by six to nine months of age (Brito et al., 2016). These results are in line with and support the notion of the profound influence of early experiences and environments on brain development, all of which occur years before children enter our traditional school system. They also underscore the importance of policies that promote prevention (rather than remediation) and positively impact the earliest learning environments of all children, beginning at birth.

\section{The epicenter of the solution: when and with whom should policy-makers intervene?}

The ultimate paradox of the early childhood space (ages $0-5$ ) is that it centers on parents. Policy-makers need to intervene early, beginning at birth, and target parental investment. Research points to differentials in parent/caregiver input to be a critical - and often bypassed - approach for lessening the achievement gap (Noble, 2016). Not only do early childhood policies start too late, but also the dominant focus of the interventions is on the children and not the parents.

Ultimately, two significant parent and caregiver variables have been found to mediate SES impacts on foundational brain development: (1) the quantity and quality of the early language environment, which primarily impacts the brain's language cortex; and (2) the level of stress within a household, which affects the hippocampus and prefrontal cortex (see Figure 2) (Noble, 2016). This research points to the need for enhancing caregiver capacity through an intentional focus on the behavioral inputs necessary for optimizing children's foundational brain development. While many known environmental factors affect parenting choices (e.g. employment, nutrition, access to quality health care, housing, and mental health), social policies that invest in parents and increase the quality and quantity of parental investment in children's development are key drivers for improving long-term outcomes for children (ages 0-5) and altering the current landscape in which educational disparities emerge in infancy.

As noted by James Heckman, "The longer society waits to intervene in the life cycle of a disadvantaged child, the more costly it is to remediate the disadvantage" (Heckman, 2008). Consistent with this view is evidence gathered from a select glimpse of the literature. In Figure 3, we summarize numerous field experiments from the literature to provide an indication of the return 


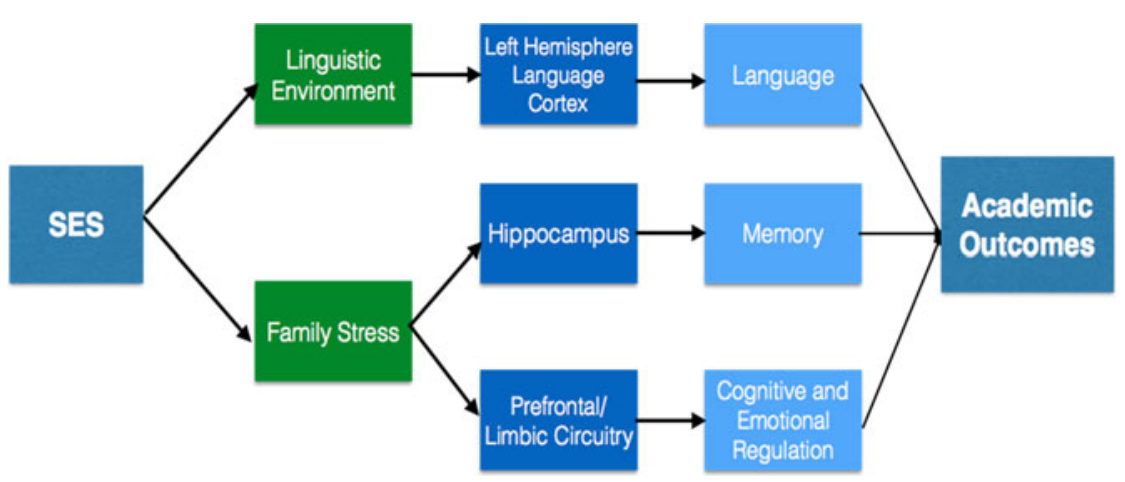

Figure 2. Parent/caregiver variables that mediate socioeconomic status (SES) impacts on brain development

on investment over the education cycle. In the top panel of Figure 3, we standardize effects to show results across a number of field experiments. We include results from studies that report the standardized effect on academic outcomes (either Grade Point Average, scores on standardized tests, or matriculation rates) or reported the numbers necessary to standardize reported effects. The interventions ranged from financial incentives for students or teachers to extra mentoring and academic support for students. We also include a bestfit regression line.

An interesting relationship is uncovered in Figure 3: the effect sizes appear to be moderately larger for programs that involve younger children. This relationship is in accord with insights from the body of scientific work discussed above. Of course, policies are not made in a vacuum - program costs need to be considered before advancing public policy prescriptions. In the lower panel of Figure 3, we adjust for program cost. When adjusted for cost, the pattern strengthens, with the bestfit line displaying an even steeper downward slope, suggesting that when costs are accounted for, there is an even deeper case for earlier educational programs.

In the end, one should consider Figure 3 as provocative, but merely suggestive, as we are confident that the literature includes a number of other pertinent studies. Nonetheless, our assembly of studies does point to the need to carefully assess the literature at large and gives promise to the notion that education must come earlier than is currently conceived.

\section{Inserting behavioral economics into early childhood education (ages $0-5$ )}

Despite the compelling brain research and causal empirical evidence, the current educational system in the United States focuses on preschool (ages 3-5) 

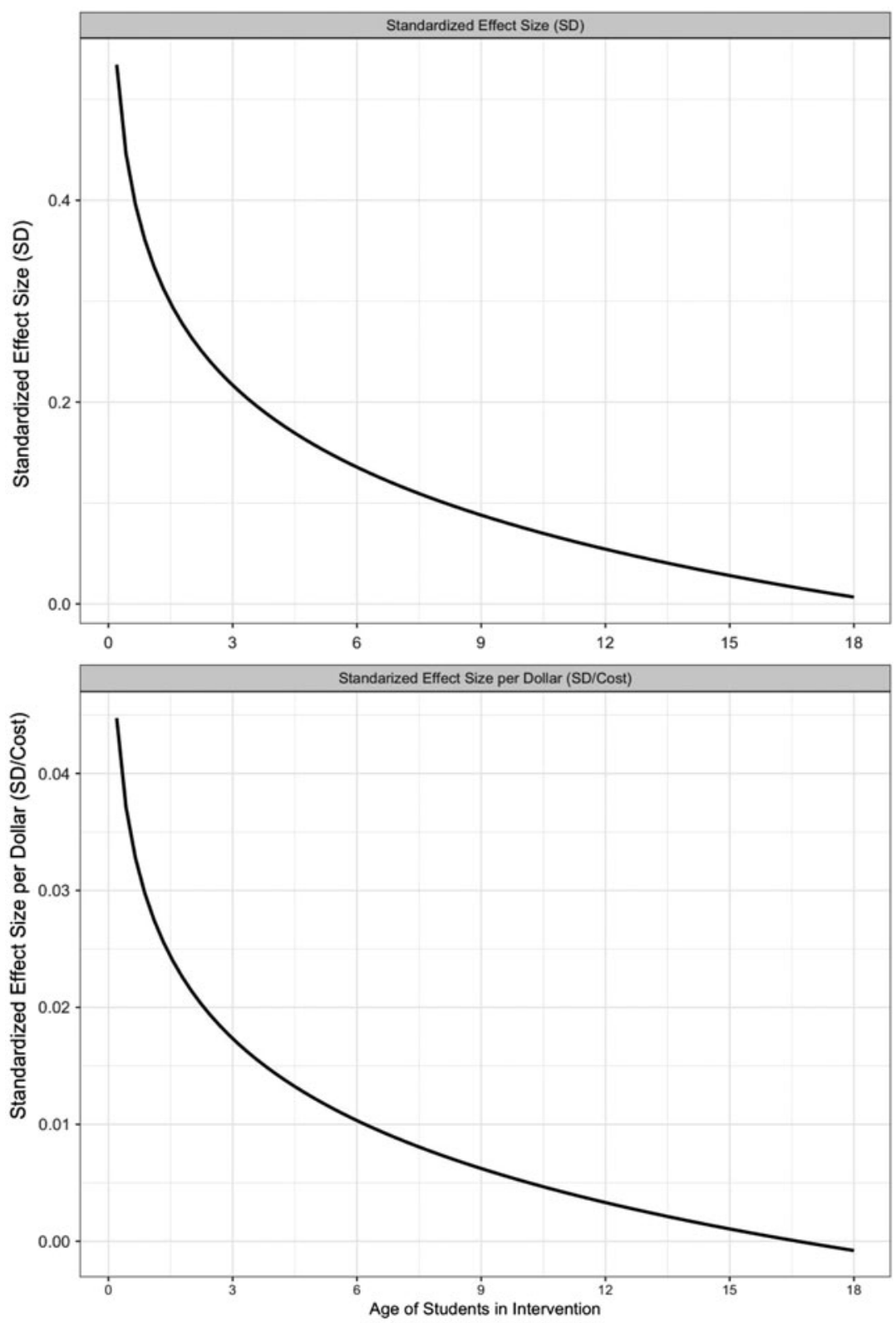

Figure 3. A glimpse of program returns over education cycles. Standardized effect of an intervention is reported as a function of student age in an intervention. A log-linear best-fit line is plotted over the standardized effects to demonstrate the declining effectiveness of interventions as children get older. Please contact the authors for further details 
through to college and misses the most critical window for prevention. Moreover, because preschool efforts typically mirror those of the formal K-12 system (ages 6-18), they have yet to impact parents in a systematic and sustained way. As educator and social scientist Frank Furstenberg argues, the historical impact of policies designed "to alter family processes to reduce educational inequality [has been] largely inefficient" (Furstenberg, 2011).

While research has only recently confirmed the pivotal role of caregivers in foundational brain development, the divide between what we know to be the tremendous influence of parents on children's developmental trajectories and the way in which generalized parenting interventions have historically tried to respond - and fallen short - compels us to redefine our early childhood policy approach. We seek to leverage new behavioral tools that specifically and strategically target parenting decisions toward children's foundational brain development.

Doing so at a population level necessitates a deeper understanding of how to affect behavior change among parents and caregivers of young children (ages 0 5 ). Behavioral economics offers a unique vehicle that redefines parenting as a series of decision-making events. It also provides a toolkit for rigorously field testing the ways in which these decisions can be impacted to yield positive outcomes for children. For example, while we know remarkably little about what motivates parents to engage in their children's development, we can apply behavioral nudges to test potential 'soft skills' (e.g. intrinsic motivations and preferences), which are proving essential to the design of high-efficacy parent interventions. In the below discussion, we explore how nudges such as text message reminders, goal setting, and identity priming in the University of Chicago Medicine Thirty Million Words ${ }^{\circledR}$ Initiative (TMW) and how financial incentives in the Chicago Heights Early Childhood Center (CHECC) project, among others, play key roles in the effectiveness of parent programs.

The overarching goal of bringing a behavioral economics lens to the $0-5$ years of age space is to reduce the gap between parental intention and behavior, specifically enabling parents to take full advantage of social supports and parenting interventions that strengthen children's foundational brain development in the most critical years leading up to preschool and beyond. To achieve this goal, we first need to understand the limitations of the current landscape of parent-directed interventions.

\section{Barriers to parent engagement in the current early childhood landscape}

The two primary federally funded conduits for impacting parenting in the United States at the national level are via the parent engagement components of Early Head Start (EHS) and home-visiting programs, which provide guidance to individual high-risk families. Despite the many documented positive impacts, 
including increased time spent by parents reading and doing math activities with their children (Gelber \& Isen, 2011), EHS programs struggle with high levels of attrition, particularly among the most vulnerable populations (e.g. families living below $50 \%$ of the poverty line, experiencing high mobility, or being headed by a mother under the age of 20). A US Department of Health and Human Services (HHS)-commissioned study reports that $35 \%$ of pregnant women who enroll in EHS leave the program early, with 16 months as the average length of program duration (Caronongan et al., 2014).

Home-visiting programs, on the other hand, expanded rapidly through the Affordable Care Act of 2010, with nearly 250,000 US parents and children served in 2015 alone (a number that has quadrupled since 2012) (HRSA, 2016). Home-visiting programs provide guidance on parenting behaviors, school readiness, health, and social services to individual high-risk families, but demonstrate a wide range of effectiveness and a lack of high-quality efficacy studies. For example, in an ongoing HHS review, out of 42 home-visiting models identified, less than half $(n=19)$ were rigorously evaluated and showed favorable results (Avellar et al., 2016). Both challenges - parent attrition (and resulting lack of uptake) and lack of high-efficacy programs - highlight the need for a new behavioral research approach that can iteratively redesign interventions to achieve the intended outcomes.

\section{Applying behavioral economics to overcome attrition and optimize behavior change}

The power of the behavioral economics lens is that it provides a more realistic model of parent decision-making than the traditional model of rationality, which assumes that parents will optimize their investment in their children based on all available information and by taking future outcomes into account. Research now shows that underlying psychological causes (e.g. selfcontrol problems, present-mindedness, cognitive overload, and hassle factors) play a role in individual decision-making, which has direct relevance for social policy (Richburg-Hayes et al., 2014). An understanding of how these underlying causes of decisions factor into parent decision-making will allow us to develop low-cost, light-touch interventions aimed at improving parent investment in children. Such nudges could include informational framing changes, reminders, commitment tools, and incentives.

For example, a robust body of literature shows that parenting decisions are consistently affected by cognitive biases that discount future gains more than future losses. Models incorporating temptation impulses, which provide a reason for the observed difficulty people have with exercising, eating healthily, or saving more, are among the most prominent in behavioral economics (Frederick et al., 
2002). Similarly, parents may have difficulty investing in their children when the rewards from parent investment are accrued far in the future. Providing parents with immediate incentives in the present may help overcome high future discount rates. In addition, field experiments can explore the impact of a sequence of behavioral nudges; for example, if it is more effective to use identity priming early in interventions and to add incentives later to influence ongoing parent participation and reduce attrition (Richburg-Hayes et al., 2014).

In this manner, behavioral nudges are also showing great promise when used as a set of coordinated tools within a single intervention to stimulate targeted parenting behaviors that boost children's cognitive development. The TMW, for example, develops evidence-based, multimedia interventions that target specific behavioral inputs to optimize children's foundational brain development, particularly targeting low-income parents and high-need communities.

Developed through a data-driven, iterative process that engaged multiple stakeholders, including parents and community members, the TMW flagship curriculum translates emerging brain science into practical lessons that allow parents/caregivers to gain critical knowledge about brain development and increase both the quantity and quality of parent-child interactions. Animations and real-life videos of parents and children interacting highlight the targeted parenting behavior. Rigorously tested in randomized control trials, TMW parent-directed interventions have been shown to: (1) enhance parent knowledge of children's cognitive development; (2) improve the quality and quantity of parent-child interactions; and (3) strengthen children's early language environments (Suskind et al., 2016).

Rooted in the economic understanding of scarcity - that poverty essentially drains cognitive resources as well as financial resources (Shah et al., 2012; Mullainathan \& Shafir, 2013; Gennetian \& Shafir, 2015) - TMW interventions leverage a cohesive set of behavioral nudges to shape overall parenting behavior (see Table 1). For example, by teaching the key concepts of the TMW curriculum with the same central behavioral tools (i.e. the TMW 3Ts [Tune In, Talk More, Take Turns]), TMW reduces the cognitive load of the intervention on participants. The use of weekly quantitative linguistic feedback (via a digital recorder that tracks parental input and parent-child interactions) facilitates effective short-term goal setting and longer-term delay of gratification.

Personalized text messages are also used as tools to remind parents of the desired behavior change. Moreover, because research shows that parents often underestimate the future benefit of participation in parent-directed interventions (Gennetian et al., 2016), the use of regular linguistic feedback combined with identity priming and a focus on present-mindedness enables TMW parents to track their progress, as well as their child's immediate outcomes - all of which increases uptake and reduces the likelihood of attrition. Post-intervention measures from TMW randomized controlled trials (RCTs) 


\section{Table 1. The University of Chicago Medicine Thirty Million Words ${ }^{\circledR}$ Initiative (TMW) alignment with behavioral nudges}

\begin{tabular}{|c|c|c|}
\hline $\begin{array}{l}\text { Behavioral } \\
\text { concepts }\end{array}$ & TMW behavioral nudge & Description of TMW behavioral nudge \\
\hline Cognitive load & $\begin{array}{l}\text { TMW 3Ts: Tune In Talk } \\
\text { More Take Turns }\end{array}$ & $\begin{array}{l}\text { Parent/caregivers learn the TMW } 3 \text { Ts, evidence- } \\
\text { based strategies that constitute the core concepts of } \\
\text { the curriculum. They were designed to be a set of } \\
\text { three easy-to-remember and easy-to-understand } \\
\text { strategies that parents can readily implement into } \\
\text { their daily routines }\end{array}$ \\
\hline Present bias & Delay of gratification & $\begin{array}{l}\text { Each module in the TMW curriculum emphasizes the } \\
\text { importance of what parents can do/need to do now } \\
\text { and how their interactions with their children will } \\
\text { positively impact their child's future development }\end{array}$ \\
\hline Plan-making & $\begin{array}{l}\text { Weekly linguistic feedback } \\
\text { and goal-setting }\end{array}$ & $\begin{array}{l}\text { A digital recorder, the Language Environment } \\
\text { Analysis (LENA; like a linguistic pedometer), pro- } \\
\text { vides immediate evidence of a child's language } \\
\text { environment. Weekly LENA reports give parents } \\
\text { targeted feedback on their use of the TMW 3Ts and } \\
\text { overall input and are used to set goals for continued } \\
\text { improvement }\end{array}$ \\
\hline Framing & Identity priming & $\begin{array}{l}\text { All TMW messaging is parent-centered, aiming to } \\
\text { motivate parents to use the power of their words to } \\
\text { improve their child's development }\end{array}$ \\
\hline Reminder & Personalized text messages & $\begin{array}{l}\text { Parents/caregivers receive regular text messages to } \\
\text { remind them of the weekly goals they set (e.g. } \\
\text { "We're going to talk more to my son during dinner," } \\
\text { or, "I'm going to tune into what my child is saying } \\
\text { and build on her curiosity") }\end{array}$ \\
\hline
\end{tabular}

reveal that the new parenting behaviors were sustained over time, leading to improved outcomes for children during the most crucial time for brain development.

Other experimental interventions are also using behavioral economic tools to impact parenting decisions, specifically behaviors linked to children's brain development and executive function skill formation. Play and Learning Strategies (PALS), for example, has shown impacts on the quantity and quality of language input, including long-term cognitive outcomes for children whose parents participated in PALS (Landry et al., 2008). Similarly, the Parents and Children Together (PACT) study, which used multiple nudges including goal-setting, visual recognition, and daily text reminders, more than doubled the amount of time Head Start parents read aloud to their children (Mayer et al., 2015).

To further affect behavior change, self-identity nudges are being successfully used to support parents who seek help. The Triple P system, for example, uses a 
public media and communications strategy to promote positive parenting messages within specific communities and across the nation. This dissemination plan specifically acknowledges the difficulties of parenting, destigmatizes the need for parents to get help, and supplies much-needed information to parents (Sanders, 1999; Sanders et al., 2002).

By embedding a coordinated set of behavioral tools into parenting interventions, behavioral science continues to reduce the gap between parent intention and behavior. Interventions specifically targeting parent behaviors linked to child executive function development have also shown positive impacts on child outcomes. The CHECC project was an RCT that incorporated treatment arms in which parents of children ages 3-5 received bi-monthly group-based instruction on how to teach their children at home. Importantly, parents received financial incentives for attending the program, engaging in program 'homework' activities, and based on their child's performance on interim incentives. The program significantly improved parental investment and produced positive outcomes for children's non-cognitive development (Fryer et al., 2015). The CHECC project also included a treatment arm focused on enhancing investment in both schooling and parents - Cog-X - in which children attended a half-day preschool while their parents attended group-based instruction aimed at scaffolding the learning at home. Cog-X improved child cognitive and non-cognitive abilities (Fryer et al., 2017). Importantly, attrition was low in these programs due partly to the financial incentives provided.

\section{Applying behavioral economics to large-scale interventions and statewide policies}

By applying the use of behavioral tools to the design and implementation of large-scale social service programs, the Behavioral Interventions to Advance Self-Sufficiency (BIAS) project demonstrates the promise of using behavioral economics to redesign statewide policies and improve outcomes for lowincome families and children. Sponsored by the Office of Planning, Research and Evaluation (OPRE) of the Administration for Children and Families (ACF) in the United States, the BIAS model uses a four-step process called 'behavioral diagnosis and design' (Richburg-Hayes et al., 2014). Program leaders and BIAS researchers identify specific points of participant 'drop-off' (i.e. attrition) or 'bottlenecks' where the program is not achieving the desired outcomes. Then, using feedback from participants and field staff, the team explores possible behavioral explanations that are related to decision-making processes. In the last two steps, behavioral interventions are specifically designed to address the hypotheses and then tested using RCTs to determine the impact of each behavioral nudge. At the core of this multistep approach 
is the use of behavioral nudges in large-scale interventions to impact human tendencies in decision-making and dramatically increase effectiveness.

In its first two years, project BIAS has launched 15 RCTs that have tested behavioral theories in seven states with close to 100,000 participants. For example, in one case study designed to improve child support, the following behavioral tools were used to investigate 'drop-off' points for participants and programmatic 'bottlenecks': deliberation costs and the ostrich effect (preventing participants from reading reminder notices); cognitive overload (inhibiting comprehension of reminder notices); and hot-cold empathy (preventing participants from keeping their appointment with the lawyer). Outcomes from each of the RCTs yielded significant insight into how to sustain participant engagement, increase program effectiveness, and optimize participant decision-making processes. Similar BIAS projects have explored how to improve child care recertification and to increase participant engagement in the job search programs required by Temporary Assistance for Needy Families (TANF). The success of this model highlights the power of behavioral economics to drive policy development and large-scale implementation through innovative, low-cost, evidence-based nudges that propel participants to make decisions in their best interests and the interests of society at large (Richburg-Hayes et al., 2014).

In a similar way, the application of behavioral economics to parent-directed interventions in the early childhood space holds great promise for improving outcomes, specifically for parent investment in child development and children's foundational brain development. In line with national policy demands, high-quality, low-cost evaluation as well as rapid and iterative redesign will drive behavioral solutions for evaluating and improving existing early childhood programs for efficacy and scalability, much like the BIAS project, and replicating, adopting, and bringing successful evidence-based interventions to scale. This use of field experiments to explore behavioral nudges toward parent engagement and decision-making reveals the best scientific causal evidence of impact. This is particularly important in the early childhood space because much of the work showing relationships between SES, parent investment, and child outcomes has been correlational rather than causal (e.g. Hart \& Risley, 1995) and rigorous data that more aptly isolate variables need to be collected in order to inform policy development and demonstrate a return on investment.

\section{Reimagining early childhood (ages $0-5$ ): a public health approach}

Impacting parent-child interaction at a population level is a monumental task in size and scale and requires a rethinking of our early childhood approach. 
Given the magnitude of the issue - that foundational brain development plays a key role in the development of all children and that the growing number of families living in poverty disproportionally affects the brain development of disadvantaged children - we need to respond to this public health crisis with a public health approach, one that optimizes children's early learning through parental investment.

Research shows that learning begins on the first day of life - and not the first day of school - and the current early childhood landscape is not designed to reach all families. Despite the power of evidence for social learning in parent-directed interventions, research suggests that the vast majority of parents do not receive any type of parenting support, particularly from evidence-based programs (Taylor \& Biglan, 1998; Sanders, 1999; Prinz \& Jones, 2003; Prinz \& Dumas, 2004).

Arguably, when too few families derive the benefits of evidence-based parenting programs, the potential of all parenting programs to yield positive outcomes for parents and children is dramatically curtailed (Biglan \& Metzler, 1998). To affect parent investment at a population level requires a multifaceted, systems-based, data-driven approach for early learning that leverages insights from behavioral economics and the science of scaling.

As an example, the current suite of complementary TMW interventions, all of which embed behavioral economics tools, are aimed at sustained behavior change via a public health approach. By adapting TMW-Home Visiting, these evidence-based interventions overlay existing health, education, and human services systems in order to reach families in settings they frequent and offer multiple touchpoints for communities in need. For example, two bilingual perinatal interventions, TMW-Newborn and TMW-Well Baby, are designed expressly for use in health care. The first is administered on maternity wards during the Universal Hearing Screening, the second during pediatric well-baby visits that follow the standard immunization schedule at one, two, four, and six months of age. Two additional interventions are currently in design: TMW-Early Learning for childcare professionals and the EHS workforce; and the community-based TMW-Spread the Words for leveraging parent social networks to develop parent advocates. The long-term goal remains the successful scaling of parenting interventions - TMW as well as others - across communities and then ultimately at the population level.

\section{Epilogue}

The lack of educational opportunities represents one of the most significant public policy issues of our time. Indeed, with today's technology, humankind might be wasting more human potential than at any time in our history, or 
at least since the dark ages. Children from low SES households score lower than their peers on academic achievement tests and suffer long-term consequences such as higher high school drop-out rates, lower entry rates to college, and lower rates of college completion (Bailey \& Dynarski, 2011). Notably, the problem starts early: low SES is correlated with significantly lower foundational brain development (cognition) emerging in the earliest years of life (ages $0-5$ ). These disparities continue into adulthood in fundamental ways, with many not achieving their human potential.

In this study, we begin by taking on the challenge of determining when policy-makers should intervene. Our evidence points to much earlier investment than is currently practiced - prevention, not remediation, is the solution. Next, we ask: how do we intervene? While a number of studies have focused on schooling interventions for children, we focus on the parents and caregivers as the primary force of change. This is because research points to differentials in caregiver and parent input as key drivers of improvement. Finally, at a more macro level, we advocate for a public health approach.

In sum, we espouse the importance of aligning early childhood policies with what the convergence of science demonstrates about young children's health and brain development and the critical role of parents therein. By considering both the science and the economies of scale, we can advance a data-driven population health approach to lessen the health and achievement gaps and improve the life course outcomes for new generations of vulnerable children.

Of course, knowledge gaps remain. In line with national policy demands, field experiments will play a key role in providing the necessary knowledge to advance optimal policies. In addition to determining what works best, how to use received results from field experiments remains of utmost import. The science of using science will drive the development of cross-sector, evidence-based delivery models that will ultimately advance children's health and foundational brain development at a population level (Al-Ubaydli et al., 2017a, 2017b, 2017c). One way to achieve field experiments at a low cost is to partner directly with school districts and take advantage of the already-collected administrative data that will become available on the children in the study as they age into school settings. Partnerships with school districts can also achieve the added benefit of shared spaces/resources to implement the intervention.

The solution that we advocate for will not be a simple one. It is more challenging to intervene with parents than it is with children, since parents can be difficult and costly to reach. Moreover, conducting adequately powered field experiments involves high effort costs, from securing partnerships with school districts, to expending resources to reach families with children ages $0-5$, to keeping these families engaged so that data on long-term impacts can 
be collected. The empirical examples that we cited come from the US context; however, the effort to improve educational disparities should be a global one. One example of cross-country work that incorporates behavioral economics in order to understand motivations for educational attainment is Gneezy et al. (2017), who provide insights into the education production function by using experimental variation in incentives to show that students in the United States are less intrinsically motivated to perform on standardized tests relative to students in China.

We speculate that under this new empirical standard, we will quickly find that it is imperative to focus on a two-generation model that begins at birth and improves outcomes for both parents/caregivers and children. As the science and economies of scale aptly reveal, early childhood education starts long before a child enters the traditional pre-K-12 school system.

\section{Financial support}

The authors disclosed receipt of the following financial support for the research, authorship, and/or publication of this article: research reported in this paper was supported by the PNC Foundation and the Hemera Foundation.

\section{References}

Al-Ubaydli, Omar, John A. List and Dana L. Suskind (2017a), 'The science of using science', In preparation for the International Economic Review.

Al-Ubaydli, Omar, John A. List and Dana L. Suskind (2017b), 'Scaling for Economists: Lessons from the non-adherence problem in the medical literature', Journal of Economic Perspectives, 31: $125-144$.

Al-Ubaydli, Omar, John A. List and Dana L. Suskind (2017c), 'What Can We Learn from Experiments? Understanding the Threats to the Scalability of Experimental Results', American Economic Review, 107: 282-286.

Avellar, Sarah, Diane Paulsell, Emily Sama-Miller, Patricia Del Grosso, Lauren Akers, Rebecca Kleinman (2016), 'Home Visiting Evidence of Effectiveness Review: Executive Summary,' OPRE Report \#2015-85a.

Bailey, Martha J. and Susan M. Dynarski (2011), Gains and gaps: Changing inequality in US college entry and completion. No. w17633. National Bureau of Economic Research.

Biglan, Anthony, and Carol W. Metzler (1998), 'A public health perspective for research on familyfocused interventions', Drug abuse prevention through family interventions. NIDA Research Monograph, 177: 430-458.

Blair, Clancy and C. Cybele Raver (2014), 'Closing the achievement gap through modification of neurocognitive and neuroendocrine function: Results from a cluster randomized controlled trial of an innovative approach to the education of children in kindergarten', PloS one 9(11): e112393.

Brito, Natalie H., William P. Fifer, Michael M. Myers, Amy J. Elliott and Kimberly G. Noble (2016), 'Associations among family socioeconomic status, EEG power at birth, and cognitive skills during infancy', Developmental cognitive neuroscience, 19: 144-151. 
Caronongan, Pia, Emily Moiduddin, Jerry West and Cheri A. Vogel. (2014), Children in Early Head Start and Head Start: A profile of early leavers. No. 9c272ceaee61450e8b43324a9e53c711. Mathematica Policy Research.

Fernald, Anne, Virginia A. Marchman and Adriana Weisleder (2013), 'SES differences in language processing skill and vocabulary are evident at 18 months', Developmental science, 16(2): 234-248.

Forget-Dubois, Nadine, Ginette Dionne, Jean-Pascal Lemelin, Daniel Pérusse, Richard E. Tremblay and Michel Boivin (2009), 'Early child language mediates the relation between home environment and school readiness', Child development, 80(3): 736-749.

Frederick, Shane, George Loewenstein and Ted O'donoghue (2002), 'Time discounting and time preference: A critical review', Journal of economic literature, 40(2): 351-401.

Fryer, Roland G. (2011), Teacher incentives and student achievement: Evidence from New York City public schools. No. w16850. National Bureau of Economic Research.

Fryer, Roland G., Steven D. Levitt and John A. List (2015), Parental incentives and early childhood achievement: a field experiment in Chicago Heights. No. w21477. National Bureau of Economic Research.

Fryer, Roland G., Steven D. Levitt, John A. List and Sally Sadoff (2012), Enhancing the efficacy of teacher incentives through loss aversion: A field experiment. No. w18237. National Bureau of Economic Research.

Fryer, Roland G., Steven D. Levitt, John A. List and Anya Samek (2017), Towards an Understanding of What Works in Preschool Education. Work in progress.

Furstenberg, Frank F. (2011), 'The challenges of finding causal links between family educational practices and schooling outcomes', Whither opportunity, 465-482.

Gelber, Alexander M., and Adam Isen (2011), Children's schooling and parents' investment in children: evidence from the head start impact study. No. w17704. National Bureau of Economic Research.

Gennetian, Lisa A., and Eldar Shafir (2015), 'The persistence of poverty in the context of financial instability: A behavioral perspective', Journal of Policy Analysis and Management, 34(4): 904-936.

Gennetian, Lisa A., Matthew Darling and J. Lawrence Aber (2016), 'Behavioral Economics and Developmental Theory: Implications for Early Childhood Interventions' (white paper). Retrieved December 30, 2016, from Behavioral Policy: https://behavioralpolicy.org/wpcontent/uploads/2016/05/BE-and-Early-Childhood-2016_working-paper-1.pdf.

Gneezy, Uri, John List, Jeff Livingston, X. Qin, Sally Sadoff and Y. Xu (2017), 'Measuring Success in Education: The Role of Effort on the Test Itself' Work in progress.

Guryan, Jonathan, Erik Hurst and Melissa Kearney (2008), 'Parental education and parental time with children', The Journal of Economic Perspectives, 22(3): 23.

Halle, Tamara, Nicole Forry, Elizabeth Hair, Kate Perper, Laura Wandner, Julia Wessel and Jessica Vick (2009), 'Disparities in early learning and development: lessons from the Early Childhood Longitudinal Study-Birth Cohort (ECLS-B)' Washington, DC: Child Trends: 1-7.

Hart, Betty and Todd R. Risley (1995), Meaningful differences in the everyday experience of young American children. Paul H Brookes Publishing.

Heckman, James J. (2000), 'Policies to foster human capital', Research in economics, 54(1): 3-56.

Heckman, James J. (2008), 'The case for investing in disadvantaged young children', Big ideas for children: Investing in our nation's future, 49-58.

HRSA. (2016), Home visiting. Retrieved from https://mchb.hrsa.gov/maternal-child-health-initiatives/home-visiting-overview

Landry, Susan H., Karen E. Smith, Paul R. Swank, and Cathy Guttentag (2008), 'A responsive parenting intervention: the optimal timing across early childhood for impacting maternal behaviors and child outcomes', Developmental psychology, 44(5): 1335. 
Levitt, Steven D., John A. List, Susanne Neckermann, and Sally Sadoff (2016), 'The behavioralist goes to school: Leveraging behavioral economics to improve educational performance', American Economic Journal: Economic Policy, 8(4): 183-219.

List, John A. and Anya Savikhin Samek (2015), 'The behavioralist as nutritionist: leveraging behavioral economics to improve child food choice and consumption', Journal of health economics, 39: $135-146$.

Lugo-Gil, Julieta and Catherine S. Tamis-LeMonda (2008), 'Family resources and parenting quality: Links to children's cognitive development across the first 3 years', Child development, 79(4): $1065-1085$.

Mayer, Susan E., Ariel Kalil, Philip Oreopoulos and Sebastian Gallegos (2015), Using behavioral insights to increase parental engagement: The parents and children together (PACT) intervention. No. w21602. National Bureau of Economic Research.

Mistry, Rashmita S., Jeremy C. Biesanz, Nina Chien, Carollee Howes and Aprile D. Benner (2008), 'Socioeconomic status, parental investments, and the cognitive and behavioral outcomes of low-income children from immigrant and native households', Early Childhood Research Quarterly, 23(2): 193-212.

Mullainathan, Sendhil and Eldar Shafir (2013), Scarcity: Why having too little means so much. Macmillan.

Murphey, D., M. Cooper, and N. Forry (2013), 'The youngest Americans: A statistical portrait of infants and toddlers in the United States' Bethesda, MD. Retrieved from Child Trends: http://documents.mccormickfoundation.org/pdf/Child-Trends-2013.pdf. Accessed December 30, 2016.

Nelson, Charles A., Charles H. Zeanah, Nathan A. Fox, Peter J. Marshall, Anna T. Smyke, and Donald Guthrie (2007), 'Cognitive recovery in socially deprived young children: The Bucharest Early Intervention Project', Science, 318(5858): 1937-1940.

Noble, Kimberly (2016), 'Socioeconomic disparities, children and brain development' (PowerPoint slides). Retrieved from https://www.youtube.com/watch?v=P7hxDEfNrHM

Noble, Kimberly G., Suzanne M. Houston, Eric Kan, and Elizabeth R. Sowell (2012), 'Neural correlates of socioeconomic status in the developing human brain', Developmental science, 15(4): 516-527.

Prinz, Ronald J., and Jean E. Dumas (2004), 'Prevention of oppositional defiant disorder and conduct disorder in children and adolescents', Handbook of interventions that work with children and adolescents: From prevention to treatment, 475-488.

Prinz, Ronald J. and Tracy L. Jones (2003), 'Family-based interventions', Conduct and oppositional defiant disorders: Epidemiology, risk factors, and treatment, 279-298.

Raver, C. Cybele, Clancy Blair and Michael Willoughby (2013), 'Poverty as a predictor of 4-yearolds' executive function: New perspectives on models of differential susceptibility', Developmental psychology, 49(2): 292.

Richburg-Hayes, Lashawn, Caitlin Anzelone, Nadine Dechausay, Saugato Datta, Alexandra Fiorillo, Louis Potok, Matthew Darling, and John Balz (2014), 'Behavioral Economics and Social Policy: Designing Innovative Solutions for Programs Supported by the Administration for Children and Families. OPRE Report No. 2014-16a' MDRC.

Sanders, Matthew R. (1999), 'Triple P-Positive Parenting Program: Towards an empirically validated multilevel parenting and family support strategy for the prevention of behavior and emotional problems in children', Clinical child and family psychology review, 2(2): 71-90.

Sanders, Matthew R., Karen MT Turner, and Carol Markie-Dadds (2002), 'The development and dissemination of the Triple P-Positive Parenting Program: A multilevel, evidence-based system of parenting and family support', Prevention Science, 3(3): 173-189.

Shah, Anuj K., Sendhil Mullainathan and Eldar Shafir (2012), 'Some consequences of having too little', Science, 338(6107): 682-685. 
Suskind, Dana L., Kristin R. Leffel, Eileen Graf, Marc W. Hernandez, Elizabeth A. Gunderson, Shannon G. Sapolich, Elizabeth Suskind, Lindsey Leininger, Susan Goldin-Meadow, and Susan C. Levine (2016), 'A parent-directed language intervention for children of low socioeconomic status: a randomized controlled pilot study', Journal of child language, 43(02): $366-406$.

Taylor, Ted K. and Anthony Biglan (1998), 'Behavioral family interventions for improving childrearing: A review of the literature for clinicians and policy makers', Clinical child and family psychology review, 1(1): 41-60.

Ursache, Alexandra, Clancy Blair and C. Cybele Raver (2012), 'The promotion of self-regulation as a means of enhancing school readiness and early achievement in children at risk for school failure', Child Development Perspectives, 6(2): 122-128.

Villena-Roldán, Benjamín and Cecilia Ríos-Aguilar (2012), Causal effects of maternal time-investment on children's cognitive outcomes. No. w285. National Bureau of Economic Research. 